\title{
Editorial
}

\section{Inaugurating Brief Communications}

In 1999, when the electronic age was blossoming, The Journal of Neuroscience launched an all-electronic section of the Journal aimed at short papers of timely interest. The intention was that once reviewed, the papers could be published quickly online. For the Journal, this was also a means to test the concept of allelectronic publishing for itself and for the Society for Neuroscience membership.

The electronic age never stands still. In the meantime, the Journal has been developing a system for all-electronic handling of manuscripts, which will reduce the time to press for all articles, and is exploring mounting all papers in press, further reducing the time for all papers in press. Despite the early enthusiasm for all-electronic journal publishing, our experiment indicates that authors still prefer to see their best work in print. It is therefore timely to fold the short articles into the print journal as well as the online version.

To distinguish the new section, it will be called Brief Communications. The goal is the same: to attract the best short papers reporting experimental results of timely interest to a broad audience in neuroscience. The papers will meet the same high standards as regular articles. Brief Communications will be subject to the same limits on length (4500 characters) and number of figures as the former Rapid Communications. Figures and/or tables are limited to a total of one printed page (e.g., four one-quarter page figures). Otherwise the Instructions for Authors will closely follow those for regular manuscripts. To highlight these articles, they will appear as a special section at the start of each journal issue, in both the print and online versions.

As an attraction to potential authors, 50 free reprints will be provided for each article. As in the case of regular articles, color deemed by the editors to be essential will be free for papers in which the first and last authors are members of the Society for Neuroscience. Membership is available on a rolling basis throughout the year (see www.sfn.org).

\section{Gordon M. Shepherd} Editor-in-Chief 